\title{
I Draw Therefore I Am: Drawing as Visual (Communication) Studies
}

\author{
Muliyadi Mahamood \& Karna Mustaqim \\ Faculty of Art and Design, University Technology MARA, \\ 40450 Shah Alam, Selangor Darul Ehsan, Malaysia \\ Email: muliyadi2004@yahoo.com
}

\begin{abstract}
This paper sets view to consider the significance of drawings as part of visual communication design. Drawing gives a chance to observe, to muse, to select and develop continuous thinking techniques. It is to present that drawing is not just a cursory to generate ideas, but it has its own energy and philosophy which deserve studying as a domain of art. In recent years, drawing has received attention; there is on the one hand a group of drawing practitioners, and on the other hand a group of drawing researchers. Drawing in design is a medium of visual and spatial thinking. Digging into research actually is a necessity for visual communication studies. It is suggested here three kinds of research approaches: research into art/design; research through art/design; and research for art/design. Indeed, it leads to four axis topics (topoi) for design studies: design practice, design product, design discourse, and design meta-discourse. A field of study called 'visual culture' which, departed from the study of critical theory and cultural studies which have set out relatively new field of study called 'visual studies'. Based upon to this perspective, visual (communication) studies should be more self-reflexive. The production of visual communication contributes to construct the visual culture in society.
\end{abstract}

Keywords: artifact; communication; drawings; visual; research.

\section{Introduction}

\subsection{What is Drawing for?}

Drawing is a fundamental training in art and design classes. Often trained in the early years of art and design courses, but its often left out to understand that drawing is not just a matter of creating a wonderful, perfect and artistic pieces. Drawing in design as determined by Kees Dorst [1] in 'Understanding Design' as a medium for visually and spatial thinking. He described several kinds of drawing that have different levels of data which, first is dealing with the general principal of an idea or design concept, second is to figure out the form of design, and third is to complete sketches that are meant for communication. On that account, drawing is a key skill to invent and construct images. Indeed, the act of drawing helps artists/designers to clarify their thoughts. Moreover, Teel

Received November $27^{\text {th }}, 2009$, Revised October $29^{\text {th }}, 2013$, Accepted for publication November $8^{\text {th }}, 2013$. Copyright @ 2013 Published by LPPM ITB, ISSN: 1978-3078, DOI: 10.5614/itbj.vad.2013.4.2.2 
Sale \& Claudia Betti [2] in Drawing: A Contemporary Approach emphasized that:

“...Drawing provides a common ground for communication; it offers us a dialogue with ourselves and with others, the viewers. It engages us on vital emotional, intellectual, and spiritual levels. Focusing on time, space, and energy, artists give material form to their ideas, and nowhere are these ideas more readily accessible than in drawings."

\subsection{Drawings-The Old New Media}

Beside making noise and creating sounds, one of the most ancient human activities is picturing what they sees, feels and think. Drawing is the primary means of symbolic communication. Ever since ancient times man has left his marks of existence through the pictures of primitive drawings (e.g. see Figure $1)$. We are already aware of the cave paintings depicting human hands and animal stylization which, spread from the Leang-Leang cave in Sulawesi (Celebes) to the famous Lasaux cave in France. It intertwined the metaphysical and the physical, and associating our thoughts and perception. As further emphasized by Primadi Tabrani [3] that:

"From its beginning visual language possesses a time dimension...This time dimension of visual drawings is what we modern man has lost, since the invention of perspective in Renaissance."

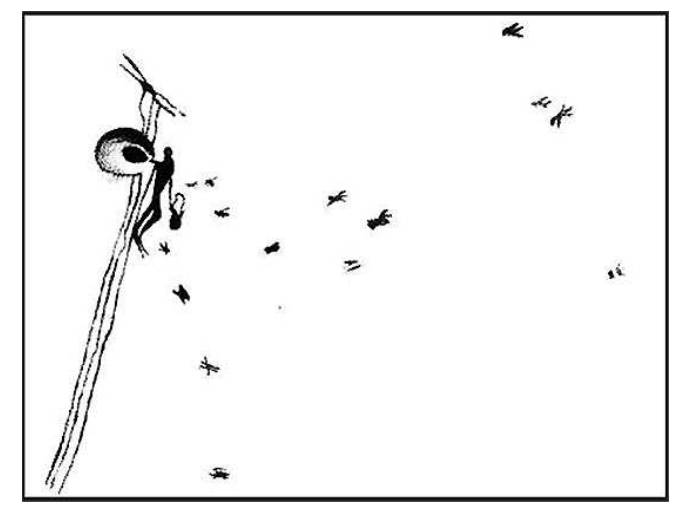

Figure 1 Honey Hunter. Cave painting in Cueve de la Arana, Valencia, Spain.

Drawing predates and embraces writing, and functions as a tool of conceptualization. The act of drawing itself has become the inner force within the human soul which has been created throughout the history of mankind; yet, it has only recently got its status as a 'valid' domain of its own. 
John A. Walker [4] reminisced that during Renaissance 'disegno' which, literally meant drawing, was considered to be the basis of all the visual arts. The works from Leonardo Da Vinci's notebooks deliberately show the valuable emergence of drawings since the Enlightment era. An artistic activity such as drawing which, made directly from the preliminary thought, is an expressive form of art that represents the idea for a piece of visionary work. Drawing is considered worth investigation on par with painting, sculpture, photograph, even architecture.

\section{Domain of Drawings}

\subsection{Beyond Process-Making}

Drawing is a noun, and drawing also is a verb. The word 'drawing(s)' has both meanings, it is a lively experience as a work of art, an activity which is the axis of artist or designer works. In recent years, drawing has got back its attention; so long forgotten and now gets its turn to reincarnate again. In this two recent books, 'Drawing Now: Eight Proposition' (2002) and 'Drawing Now: Between the Lines of Contemporary Art' (2007) that accompanies the exhibitions witnessed the enthusiasm on drawings as a final form of art. At commonplace, it is a desire to find inspiration beyond the pale of what has traditionally been considered fine art, like the vernacular forms of mass culture, such as decoration, comics, architectural drafting or kinds of drawing often treated with negligence (e.g. see Figure 2).

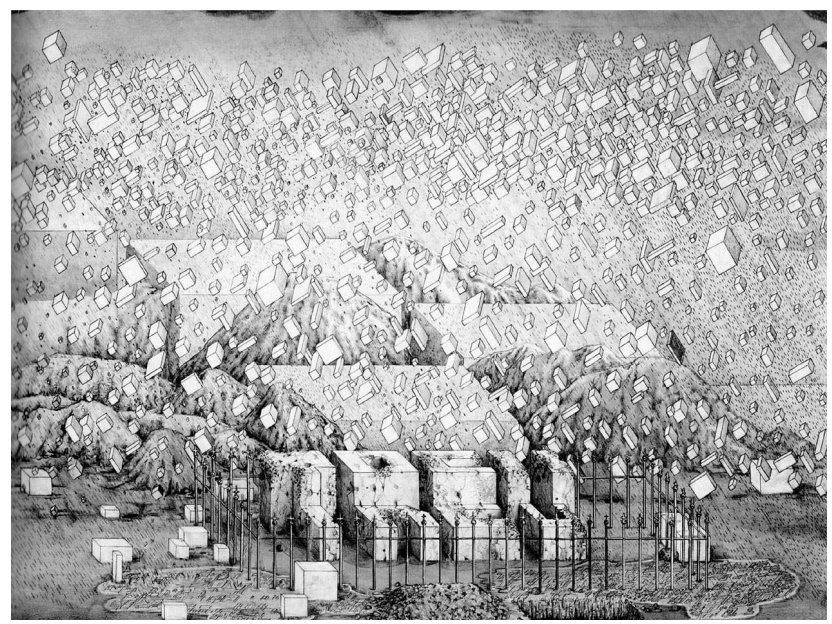

Figure 2 Paul Noble (1997-2000). Trev. 143 x $150 \mathrm{~cm}$. Pencil on paper. In Hoptman, L. [5]. Drawing Now: Eight Propositions. New York: The Museum of Modern Art. 
Many reflexive questions about the domain of drawing have emerged and require further investigation. Some interesting publications that designate the meaning of drawings beyond the art practice are: 'What is Drawing?' (2003) an exhibition created by Angela Kingston with cooperation with artists with different background such as Lucy Gunning (video art), Claude Heath (painter) and Rae Smith (designer). Meanwhile, a critical survey by Phaidon with the help from a group of curators, critics and selected museum art directors, with the most current drawings from 109 world artists put into a collection called: 'Vitamin D: New Perspectives in Drawing'(2005) in which, Emma Dexter, the book editor and a curator at Tate Modern stated that the two most significant artists: Raymond Pettitbon and Paul Nobel are able to produce monumental bodies of work that could rival any other medium in terms of scale or ambition.

Also there is 'An Atlas of Drawing: Transforming Chronologies' (2006) which is also an exhibition held in MoMA (Museum of Modern Art - New York) curated by Luis Perez-Oramas that performed a mapping of the relationship between the current works and the classical works. Then, another noteworthy investigation on the status of drawing is 'The Drawing Book, A Survey of Drawing: A Primary Means of Expressions'(2006) edited by Tania Kovats [6] with the participation from various professions such as artists, architects, sculptors, scientist, filmmaker, and other thinkers of all descriptions.

\subsection{The Research Networks}

Analysing children's art is a fascinating research, as Rhoda Kellogg [7] and Tabrani [3] suspected that many of the symbolic expressions done by children have similarities with ancient cave painting and art from indigenous people (e.g. see Figure 3). Another interesting study, John M. Kennedy [8] following some Rudolf Arnheim (1990) goals of the study of perception, pictures and touch, has employed the ideas by doing haptic research on drawing and blind people. Currently, among the scholars who had paid attention to the practice of drawing and the drawing research is Steve Garner (2008), editor of 'Writing in Drawing: Essay on Drawing Practice and Research'. For instance there were two groups of people concerning drawings: one group of drawing practitioners, and on the other hand drawing researchers. Such a book as Drawing on Conversation by Jac Saorsa (2009) was actually a doctorate research in Loughborough University that used drawing as a method of exploring and interpreting ordinary verbal interaction with several well-known artists. Several groups of study or initiated cooperation amongst scholars and practitioners have grown up.

Notably for instance, The International Drawing Research Initiative (IDRI) which is a consortium created to advance research into and through the discipline of drawing with founding members such as (College of Fine Arts) 
COFA, UNSW in Sydney, (China Central Academy of Fine Arts) CAFA in Beijing and (Glasgow School of Art) GSA; and The Drawing Research Network (DRN) which is a loose affiliation of individuals and institutions who are involved in some way with drawing research. Some participants are based in universities and colleges of art and design, and other participants simply have an interest in drawing and the drawing process which might include making, thinking and communicating on drawings.

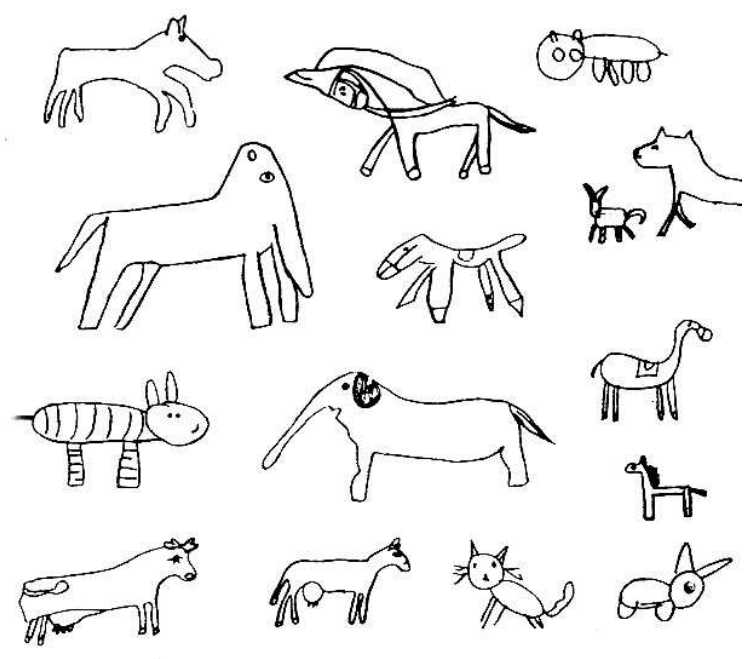

Figure 3 Animals drawings by five to seven year old children. In Kellogg [7]. Analyzing Children's Art, p.154.

\section{Drawings as a Medium of Research}

\subsection{Types of Drawings}

Sale \& Betti [2] suggested that traditionally drawings are classified into four types, first, that investigate, study, and question the real, visible, tangible world. Second, that record objects and events. Third, that communicates ideas. And fourth, that are transcriptions from memory - a way of collecting and keeping impressions and ideas, a way of making visible the world of imagination. Not only artists/designers are interested in drawings, but also doctors, scientists, engineers, technicians and even carpenters embrace the use of drawings. They assert drawings into two broadest parts: subjective drawings that emphasizes the emotions; on the other hand, thereof objective drawings that uphold conveying information as more important issues. The process of drawing amplifies an empowerment of our visual consciousness. Awareness is about both knowing how we feel about things and also understanding how things actually occurred. 
The ability to draw visible objects needs at least five perceptual skills. According to Betty Edwards [9] in The New Drawing on the Right Side of the Brain, the ability to draw possibly reflects an equally significant change in the ability to perceive. The five perceptual skills are the perception of edges, the perception of spaces, the perception of relationships, the perception of lights and shadows, and the perception of the whole (gestalt). On the relation of seeing and visualizing what we see, Laurie Olin note that:

“...drawing is a way of thinking while acting, or of thinking through acting....is about seeing and visualizing. It's about memory and finding a sequence of marks that engage observation and thought..." [10]

\subsection{Works of Drawings}

Thereby, drawing is a significant part of the design process before coming up with any solution. Drawing is the way to observe, to records and to think. In addition, drawing is a conceptualization, generatively processes and selectively progressive methods. An artist who appraised drawing as a lively method is Katshushika Hokusai (1760-1849), a famous Japanese woodblock artist (ukiyoe). He observed and captured almost everything that passed before his eyes as an aesthetics research which involves art and life. The collections of his drawings were published into 15 series called 'Manga' within 1814 till 1878. In modern time, one of the Japanese genius graphic designers who followed this tradition was Shigeo Fukuda (1932-2009) by producing optical illusion drawings.

Recently, Seymour Chwast published his long established career as an influential illustrator to the visual culture in 'Seymour: The Obsessive Images of Seymour' (2009). His partner at Push Pin Studio, a legendary graphic design studio based on New York, Milton Glaser creator of the famous I Love New York logo in Drawing is thinking gave simply a thought that drawing was not simply a way to represent reality but indeed it is a better way to understand and experience the world.

As we might see, it is obvious that the limited appreciation to drawings was not simply a process to produce a product. Rather, the drawing itself is a valuable independent work which is made before the sculptor crafts, before the writer writes, before the designer designs, before the painter paints. Drawing is ability to synchronizing thought, feelings, body movement, tools and materials. On tissue papers, wall surfaces, fields of grass or stones, bed sheet, kitchen table, or on the graphic tablet. The drawing is a symbolic communication which uses any medium, on any surfaces, at any scale to communicate anything possible (e.g. see Figure 4). 


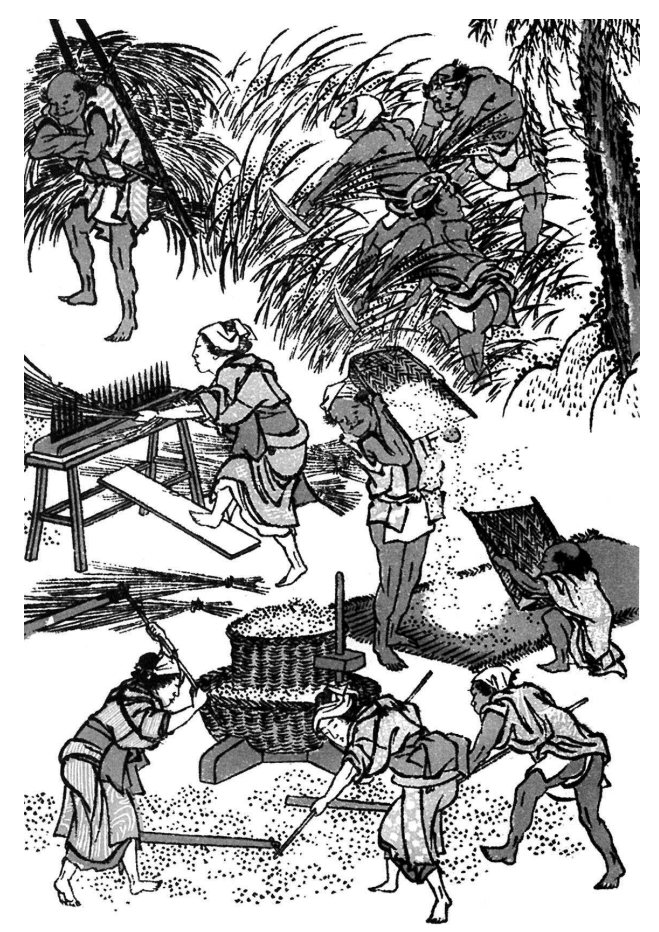

Figure 4 Katsushika Hokusai (1815). Workers harvesting rice. Woodcut. In Treib [10]. Thinking/Drawing, p.22.

\section{$4 \quad$ Research in Design Studies}

\subsection{Research Approaches}

It is a necessity to dig into research in visual communication design. This must be done along with design practice and education. Professor Christopher Frayling (1993), of Royal College of Art had adopted the art education concept from Herbert Read (1893-1968), into the realm of research on art and design. He suggested three kinds of research approaches: research into art/design; research through art/design; and research for (as) art/design.

Research into art/design is usually done in postgraduate studies, including history, aesthetics or perceptual study, and criticism, or any other theoretical perspectives on art and design.

Then, research through the art practiceled or designing in studio project which is still in great debates in academe according to the validity of the methods. This 
research practice is distinguished as the taking of something outside of the art and/design such as behavior of materials, customized technology, or documenting studio experiment, and translating it through artistic medium or designs.

The step by step recording is crucial in research through art/design for its documentation as essential component to gain respective qualification for reliability or trustworthiness in this type of research. The criteria of original contribution to a communicable knowledge are also another significant issue.

The last one is research for art/design means the primary conveyor attainment is producing an artwork or a design's object. This type of research is most suitable for undergraduate studies. According to this, Victor Margolin (1997), a design historian from the University of Illinois, Chicago, later proposed four axis topics (topoi) for design studies: design practice, design product, design discourse, and design metadiscourse [11].

\subsection{Design Knowledge}

Most of the time, people are attracted to art and design for the sake of its final "glossy" products display. While the process that might take times to do investigation, analyzing and knowledge gaining through searching and researching are often left out unaware by public in general. Dangerously, it could direct art and design too much to the practicality side. The drawings as the process, research or generating ideas and gaining knowledge from the field of study were not given much attention as it might deserve. When looking at a work, both happened in the real world or the educational institution that the practitioner or educator often rely their judgment on personal experiences and subjective intuition. Therefore, its urgency to build a reliable framework is for evaluating art and design research properly (e.g. see Figure 5). The following quotation from Design: A Very Short Introduction by John Heskett [12] reflects this worry:

"...however, that in many disciplines the kind of knowledge based on experience and insight - tacit knowledge - can be a vital repository of enormous potential. Much design knowledge is indeed of this kind, although this does not mean ability to design should be limited to the tacit dimension. There is a vital need to extend alternatives forms of knowledge in design that can be structured and communicated - in other words, coded knowledge....Most practical disciplines, such as architecture and engineering, have a body of basic knowledge and theory about what the practice is and does that can served as a platform, a 
starting point, for any student or interested layman. The absence of a similar basis in design is one of the greatest problems it faces."

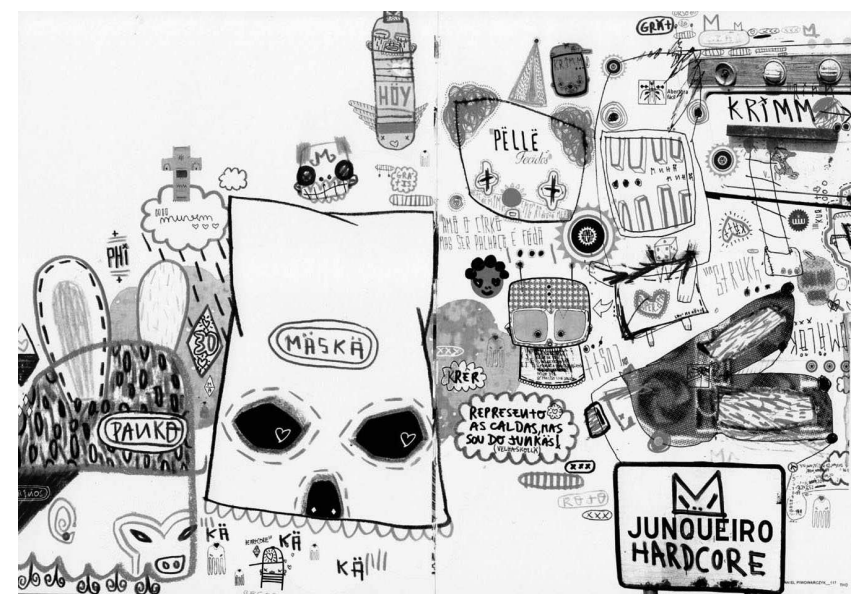

Figure 5 Nuno Valerio. Untitled. In Rojo®Ipon. Sintonison S.L., Barcelona, Spain.

\section{I Draw Therefore I Am}

\subsection{Drawing as Thinking}

Frequently, drawing is recognized as the synthetic of how the visual world is being observed, its visual appearance. Yet, a picture could possibly be more than just a representation of appearance. Subjectivity and reflexivity are primal instincts to an artist or designer. Yet, our society has put belief onto objective methods in problem solving rather than using reflexive methods which are more subjective. It is true that the capability of market research along with psychological studies have developed many objective problems solving through new creative ideas. Thus, the study of user-centered design has use of sociology and anthropology approaches.

Moreover, the humanities and philosophical study help to scrutinize the understanding of design for better life. This has been called as positivist paradigm in the term described by Thomas Kuhn in The Structure of Scientific Revolution (1962) that he believed had influenced strongly the intellectual realm. It begins with revolutionary set off by René Descartes (1596-1650), Cogito ergo sum, I think therefore I am, all the sets of knowledge put the trustworthiness of evidence in a paradigm based on rationality and scientific approval as an absolute truth. This brought to the arbitrary views to divorce the 
knowledge gathered from rational thoughtfulness and knowledge gathered from empirical experiences.

This thinking spread vastly till the appearance of existentialist Jean Paul Sartre (1905-1980) who refuted the dichotomy of beings and representation, as it is absurd to pull out essence from existence. While Plato, an idealist Greek philosopher, believed that essence precedes existence in which ideas come before the physical bodies, Sartre takes it out and make reversion that thinking and existence cannot be separated.

For 'drawing' as being and also 'drawing' as an act, a counter act, a process to create imagery from minds or feelings. That process is an observation, exploration, learning, managing, and designing to make drawings appear as an artifact (representation). But when one starts to draw, he/she tends to stop thinking. He/she just does it, the drawing appears just as it is. Drawing is thinking not because we are thinking through drawing, but we often stop to think while drawing (e.g. see Figure 6). This is the most creative act moment which probably closer to what Heidegger [13] calls thinking, "We can learn only if we can unlearn at the same time....we can learn thinking only if we can radically unlearn what thinking has been traditionally."

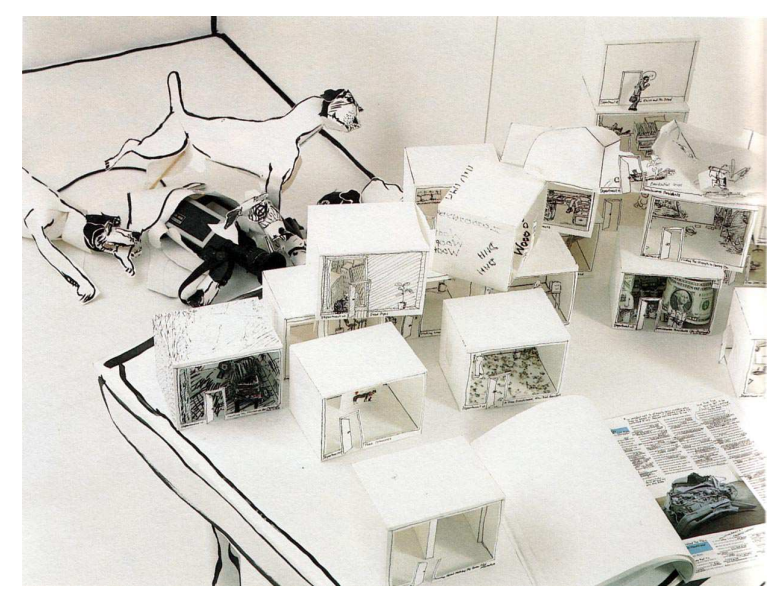

Figure 6 Gareth James (1997). Department of Everyone Getting Along. Ink on paper. In Dexter, E. \& Burton, J. [14]. Vitamin D: New Perspectives in Drawing. London and New York: Phaidon

As stated before, along with history, mankind has drawn many artifacts on the earth surface. From the prehistoric cave paintings to the skyscraper towers or golf courses, man left his trace around the globe. These human drawings are one of the very existences founded on earth to prove that mankind exists. Humans 
use drawing to denote their existence within a space as a means to mark a territory.

Chaterine Dee, a senior lecture in landscape architecture at the University of Sheffiled sees an analogous relation between the act of marking on papers, and the marking of territory on the earth's surface'[10]. She suggested that:

“...our experiences of actual environments, territories, and functions of land all affect the images we make. Differing culture and individual relationships to the land promote different kinds of drawings, while those images in turn suggest or influence new concepts of, or relations between, humans and land. This association between land and drawing media, idea and process, need to be considered critically to continually remind us that neither medium nor process is neutral."

By concerning some of the issues presented above, the next enquiry is possibly questioning the necessity of drawings in graphic design courses. To understand the distinction of graphic design from visual communication, Paul J. Nini [15] from Ohio State University explained that 'visual communication is a "process," that by its problem-solving nature includes investigative and analytical skills in the creation of communications. Graphic design focuses primarily on formmaking, while visual communication incorporates a broader series of efforts to provide rationale for form-making....that visual communication includes other types of communications beyond printed matter.'

Graphic design at the present time, either as profession or product which is broadly known as visual communication design has been pushed into the discourse of visual culture [16]. Its fundamentals have been contributed by the socialist poet, William Morris (1834-1896) since the art and crafts movement around 1880s in Britain. Guy Julier [17] in 'The Culture of Design' argued that design is:

“...a culturally specific practice which driven almost entirely by strategies of differentiation....Design culture is not fixed, homogeneous or homogenizing; rather it embrace a complex matrix of human activities, perceptions and articulations. Careful analysis of its visual, material, spatial and textual manifestation provides routes into this complexity."

\subsection{Drawings as Artifact of Thinking}

In this writing, visual communication design and graphic design were used alternately. The term graphic design is used to emphasize pragmatically of a work, and visual communication is used to articulate the communicative process, visual thinking and part of analyses. At one side, drawings are not the 
result of a graphic designing, yet it is an inevitable part of the designing process.

Accordingly, drawing and reading picture invites people to think and communicate visually through the drawings. Without a doubt, it is an obvious form of visual communication that argues the drawing itself is a 'design'. Graphic design as communication is further explained by Malcolm Barnard [16]:

"Communication in graphic design was explained as the interaction of the beliefs and values held by members of cultural groups and the formal elements of graphic design (such as shapes, lines, colors, imagery, text and layout, for example). Rather than existing, naturally and prefabricated, in graphic designs, meaning was explained as being construct in the activity of communication itself."

Drawing as a means of discovering, exploring and researching warns us not to feel secured with everything which can be measured or quantifiable. Drawings invite us to wander undiscovered imaginary sites of speculative knowledge. Olin believed 'we learn through seeing, thinking about what we see, studying, recording it in various ways of drawing by conducting research and investigations, invent problems, study them, and try out solution in and through drawing' [10]. The relationship between thinking as cognitive activity and drawing as representation, involves social dimension, psychological and aesthetics that reflect the differences of personal or social cultural background (e.g. see Figure 7).

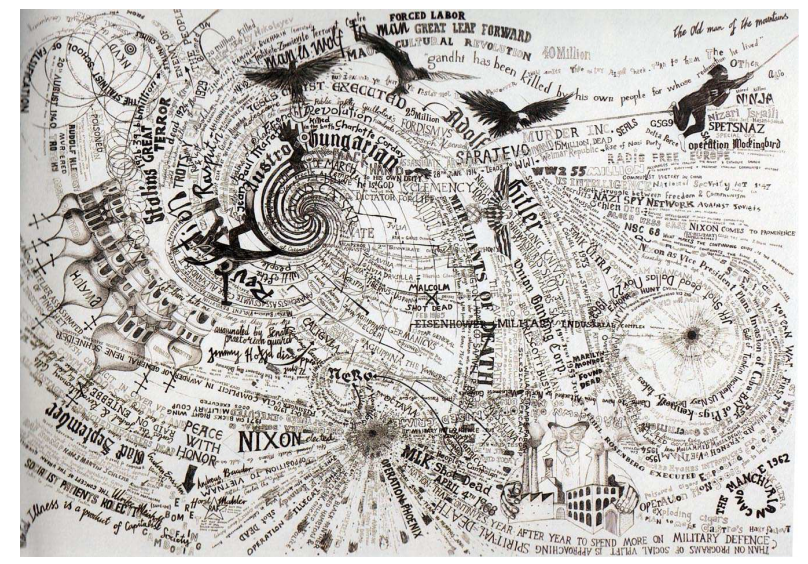

Figure 7 Dominic McGill (2004). Man is Wolf to man. 106.7 x $152 \mathrm{~cm}$. Graphite on paper. In Hoptman, L. [5]. Drawing Now: Eight Propositions. New York: The Museum of Modern Art. 
The architect historian, Mark Alan Hewitt implied drawing as a habitual tool for representing ideas and to facilitate imaginative leaps to the future [10]. In essentials, drawings and the act of drawing are being valuable as long as the existence of ideas were produced through drawings itself.

Therefore, the process and artifact of thinking unified in drawings. Perhaps the activity of drawings could become the alchemy of art and design. Perhaps, I exist, therefore I draw.

\section{Drawing Conclusions}

Sale \& Betti [2] concluded that ' the process of drawing develops a heightened awareness of the visual world, an awareness that is both subjective and objective....Art is a reflection of the culture in which it is made'. As Laura Hoptman [5] in 'Drawing Now: Eight Propositions', argues, in the last decade or so drawing has been progressively transliterated back into a noun, whereas the younger generation of artists is comfortable in its technical mastery and the manipulation of subject matter as filtered by broader visual culture. Graphic design is a field that produces and reproduces many visual images (e.g. see Figure 8).

Visual images have exhausted much of our physical and emotional energy on the act of seeing [18] and it will inevitably play a central role in the culture of the twenty first century [19]. Sturken \& Cartwright [19] suggest that culture is something fluid and interactive, "...the shared practices of a group, community, or society, through which meaning is made out of visual, aural and textual world of representation."

We live in an increasingly visual world, when verbal/written tradition gradually turn into the visual cognitive task as a result of the density of visual medium that appears everywhere (Gombrich [20], Mitchell [21], McLuhan [22]). Thus is common jargon by means of the image's power in the contemporary society. Yet, it does not mean that we have no need to read anymore, only the text or words are often regarded as part of visually too. Readability (the easiness to read) and legibility (the clarity of reading), both relate to the ability to read visual texts. It is about visually [23] more than just visualization of verbal/written words. Gillian Rose [24] firmly implied in Visual Methodology that 'we are often told that we now live in a world where knowledge as well as many forms of entertainment are visually constructed, and where what we see is as important, if not more so, than what we hear or read.'

Since the 1990's a new field of study called Visual Culture departed from the slant of critical theory and cultural studies, which later leads to another focus 
study of images namely 'visual studies' $[25,26]$. Image studies thereby marks itself out from the recent growth in visual cultural studies, which works largely from within the cultural studies perspective [27]. Visual culture has reached our inner lives which made us to alert the significance of visually around us, the environment. By crossing several disciplines, visual culture deliberately considers analytical understanding by everyone who encounters a startling array of images in daily life. Harold Pearse [28] noted that "the study of visual culture involves the critical analysis of the complex interaction of the form and content, and context of works of art, craft and design with emphasis on social and historical contexts'.

Graphic design revolves inevitably in that circle; it appears and reappears in media, technology and cultural activities. It has marked out their area of social responsibility; historically it also reflects the construction of meaning of visual images. At a glance, drawings seem to be insignificant and get rid of the cultural activity, soon forgotten and dismissed. Only few are aware that the collected drawings can become a historical records about oneselfness, works, life experience and memories. Meddle in this visual age, no matter how small the trace we left would be meaningful for the journey of mankind history. Even a piece of drawings that we left upon a raw paper might become a sign of the time in the future.

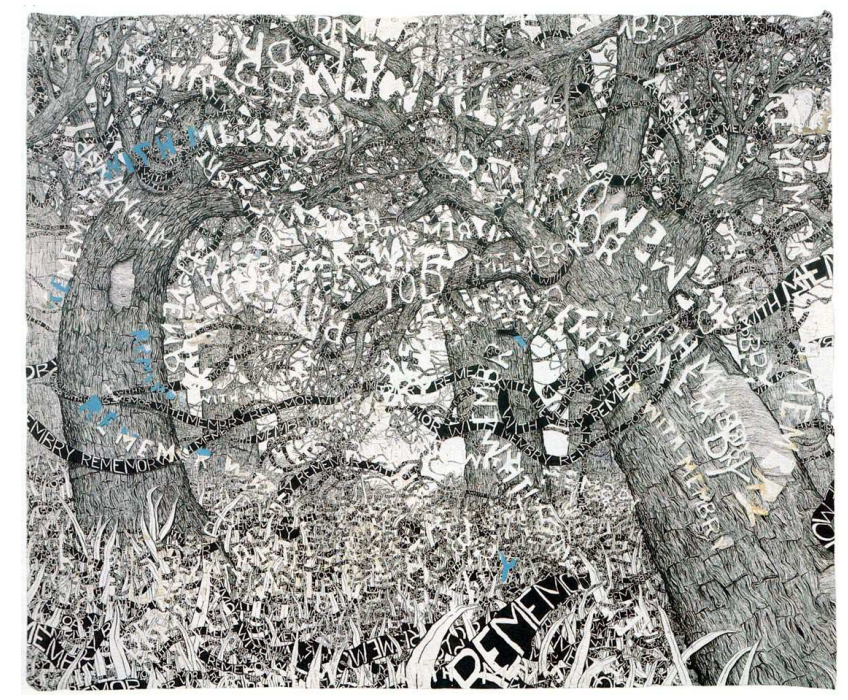

Figure 8 Trenton Doyle Hancock (2001). Remeror with Membry. 137.2 x $167.6 \mathrm{~cm}$. Acrylic on canvas. In Hoptman, L. [5]. Drawing Now: Eight Propositions. New York: The Museum of Modern Art. 
In the realm of art and design practice, drawings are not only concerned as an object of visual studies, but moreover, it is part of communication studies. Drawing as visual (communication) study might provide an exceptional occasion to the development of problem-solving skills, creativity and cultural identity which play a prominent role among the common goal of art and design education today. It is a primal being that deserved further examination. It is not just compulsory activity to the study of art and design but the drawings itself represent a wider interpretation of visual arts. It is the core study to reunderstand the communication of visual language. Last but not least, let us consider this writing itself as a drawing.

\section{References}

[1] Dorst, K. 2006. Understanding Design, English Ed.: Phyllis Crabill. Amsterdam: Bis Publisher.

[2] Sale, T. \& Betti, C. 2004. Drawing: A Contemporary Approach, $6^{\text {th }}$ Ed., California: Thomson Wadsworth.

[3] Tabrani, P. 1998. Messages from Ancient Walls, Bandung: Penerbit ITB.

[4] John A. Walker \& Judy Attfield. 1989. Design History and the History of Design, Universitas Michigan.

[5] Hoptman, L. 2002. Drawing Now: Eight Propositions, New York: The Museum of Modern Art.

[6] Kovats, T. 2007. The Drawing Book, London: Black Dog Publishing Ltd.

[7] Kellogg, R. 1969. Analyzing Children's Art, California: Mayfield Publishing Company.

[8] Kennedy, J.M. 1993. Drawing \& the Blind: Picture to Touch, New Haven \& London: Yale University Press, Available at URL: http://hdl.handle.net/1807/1021.

[9] Edwards, B. 1999. The New Drawing on the Right Side of the Brain, New York: Tarcher/Penguin.

[10] Treib, M. 2008. Thinking/Drawing: Confronting an Electronic Age, Oxon and New York: Taylor and Francis.

[11] Heller, S. 2005. The Education of a Graphic Designer, (2 ${ }^{\text {nd }}$ Ed.), New York: Allworth Press.

[12] Heskett, J.. 2002. Design: A Very Short Introduction (Very Short Introductions), Oxford University Press, 2002.

[13] Heidegger, M. 1968. What is Called Thinking? Trans, by J. Glenn Grey (Reprint 2004), New York: Harper Collins Publishers Inc.

[14] Dexter, E. \& Burton, J. 2005. Vitamin D: New Perspectives in Drawing, London and New York: Phaidon.

[15] Nini, P.J., Graphic Design or Visual Communication: Product vs Process, http://www.adcmw.org/paul_nini.html.

[16] Barnard, M. 2005. Graphic Design as Communication, Oxon: Routledge. 
[17] Julier, G. 2000. The Culture of Design, London: Sage Publications Ltd.

[18] Berger, A.A. 1998. Seeing is Believing, California: Mayfield Publishing Company.

[19] Sturken, M. \& Cartwright, L. 2001. Practices of Looking: an Introduction to Visual Culture, New York: Oxford University Press.

[20] Gombrich, E.H. \& Woodfield, R. (Ed.). 1996. The Essential Gombrich, London \& New York: Phaidon Press.

[21] Mitchell, W.J.T. 1994. Picture Theory, Chicago \& London: The University of Chicago Press.

[22] McLuhan, M. 1964. Understanding Media, 2001 Ed., London: Routledge.

[23] Mirzoeff, N. 1999. An Introduction to Visual Culture, London, New York: Routledge.

[24] Rose, G. 2001. Visual Methodology, London: Sage Publications Ltd.

[25] Schirato, T. \& Webb, J. 2004. Understanding the Visual, NSW: Allen \& Unwin, London: Sage Publications Ltd.

[26] Elkins, J. 2003. Visual Studies: A Skeptical Introduction, New York \& London: Routledge.

[27] Maghani, S., Piper, A. \& Simons, J. 2006. Images: A Reader, London: Sage Publications Ltd.

[28] Pearse, H. 2006. From Drawing to Visual Culture, Canada: McQuillQueen's University Press. 